\title{
Article \\ Study of Mixed Pollution of Haze and Dust in Jinan Based on LiDAR
}

\author{
Yuefeng Zhao, Yanqi Wang, Chunhao Liang, Jingjing Wang $\mathbb{D}^{\mathbb{D}}$, Jing Fang and Maoxia Zhou *
}

check for

updates

Citation: Zhao, Y.; Wang, Y.; Liang,

C.; Wang, J.; Fang, J.; Zhou, M. Study

of Mixed Pollution of Haze and Dust

in Jinan Based on LiDAR. Photonics

2022, 9, 144. https://doi.org/

$10.3390 /$ photonics 9030144

Received: 17 January 2022

Accepted: 24 February 2022

Published: 28 February 2022

Publisher's Note: MDPI stays neutral with regard to jurisdictional claims in published maps and institutional affiliations.

Copyright: (c) 2022 by the authors. Licensee MDPI, Basel, Switzerland. This article is an open access article distributed under the terms and conditions of the Creative Commons Attribution (CC BY) license (https:/ / creativecommons.org/licenses/by/ $4.0 /)$.
Shandong Provincial Engineering and Technical Center of Light Manipulations \& Shandong Provincial Key Laboratory of Optics and Photonic Device, School of Physics and Electronics, Shandong Normal University, Jinan 250358, China; yuefengzhao@sdnu.edu.cn (Y.Z.); 2019309014@stu.sdnu.edu.cn (Y.W.); chunhaoliang@sdnu.edu.cn (C.L.); wjj@sdnu.edu.cn (J.W.); fangjing@sdnu.edu.cn (J.F.)

* Correspondence: zhoumaoxia@sdnu.edu.cn

\begin{abstract}
From 26 March to 30 March 2021, a severe mixed haze and dust pollution process occurred in Jinan, China. Ground light detection and ranging (LiDAR) and satellite radar were used to observe and analyze the mixed pollution. In this study, a variety of data, including the pollutant concentration, meteorological factors, radiosonde data, and Cloud-Aerosol Lidar and Infrared Pathfinder Satellite Observation (CALIPSO) satellite data, as well as back-trajectory analysis, were employed to analyze the causes of the mixed pollution. The results show that, at the beginning of this weather process, fine particulate matter such as $\mathrm{PM}_{2.5}$ was the main source of pollution, and the low air mass transporting the main pollution originated from nearby cities and polluted industrial areas. After 28 March, due to the influence of a high-altitude Mongolian air mass, the concentration of coarse particulate matter such as $\mathrm{PM}_{10}$ increased significantly. The surface temperature, humidity, and wind speed also affected the accumulation of pollutants, which affected the timely diffusion of the pollution. In this study, ground LiDAR and satellite-based radar were used to detect the pollution. On the basis of a comprehensive analysis of the various meteorological factors, the formation and influence of the pollution were investigated from various perspectives. The extinction coefficient reflected the $\mathrm{PM}_{2.5}$ concentration, verifying the effectiveness of LiDAR in pollution concentration detection. The variation in the boundary layer height also had an important effect on pollution dissipation.
\end{abstract}

Keywords: Jinan; haze; dust; LiDAR; aerosols

\section{Introduction}

Aerosols are composed of suspended solid particles and gas particles in the atmosphere [1]. The characteristics of aerosols have a certain impact on the air quality and climate change, thus affecting people's daily lives [2,3]. In recent decades, with the continuous development of China's industry, human activities and fuel combustion have led to a sharp increase in the amount of particulate matter in the air [4,5]. As an important factor in the atmospheric water cycle and radiation budget, aerosols have a certain impact on the regional climate and even the global climate [6,7]. Therefore, aerosol pollution has attracted the attention of many scholars, and research on aerosols has important practical significance.

Haze is a weather phenomenon caused by fine particles in aerosols under lowhumidity conditions. Generally, the horizontal visibility is less than $10 \mathrm{~km} \mathrm{[2].} \mathrm{Haze}$ contains a large number of fine particles [8], including a high concentration of $\mathrm{PM}_{2.5}$, which can enter the respiratory tract through the alveoli, thus having an impact on human health [9]. In addition to haze, dust is also a common component of atmospheric aerosol pollution. Dust is dominated by coarse particles and has a high concentration of $\mathrm{PM}_{10}$. The concentration of dust aerosols in the atmosphere continues to rise, as seen in the frequent sandstorms that occur every spring. Aerosols not only have an important impact on atmospheric radiation and the climate, but they also have a large impact on the air quality and 
environmental ecology [10,11]. Haze and dust cause air pollution, reduce visibility, and affect people's work and lives. Thus, it is necessary to monitor aerosol pollution over the long term.

With the increasing attention paid to air pollution, many scholars have studied haze events and dust events [12]. Xiang et al. [13] studied the fine particle pollution in northern China using ground-based and vehicle-mounted light detection and ranging (LiDAR), and they simulated the air quality using the Weather Research and Forecasting (WRF) coupled with Chemistry (WRF-Chem) model. Fu et al. [14] used LiDAR and satellite observations to analyze a haze weather event in the Huainan area and found that the aerosol optical depth (AOD) was positively correlated with $\mathrm{PM}_{2.5}$, while the AOD could also reflect the pollution situation in the study area. Lei et al. [15] monitored and analyzed a dust aerosol pollution process in the main urban area of Nanchong City using ambient air quality particulate matter monitoring and meteorological observation instruments, and they simulated and analyzed the source of the dust aerosols using the Hybrid SingleParticle Lagrangian Integrated Trajectory (HYSPLIT) model. Yang et al. [16] conducted vertical remote sensing observations of dust aerosols using aerosol LiDAR and studied the three-dimensional changes and causes of dust weather, which is of great significance to the study of urban pollution.

Most of the above studies were carried out independently, and few studies have been conducted on mixed haze and dust pollution weather [17]. Unlike the single cases of haze or dust, when mixed pollution occurs, the main components of the aerosols are different; therefore, they have different optical properties, and their impact on the environment is also different. In this study, a mixed haze and dust pollution event that occurred in Jinan in March 2021 was studied; the pollutant concentrations, meteorological factors, radiosonde data, and Cloud-Aerosol Lidar and Infrared Pathfinder Satellite Observation (CALIPSO) satellite data, as well as back-trajectory analysis, were employed to analyze the causes of the mixed pollution. On the basis of the influence of the changes and interactions of the aerosols and meteorological factors on the pollution, the occurrence conditions and mechanisms of such mixed pollution events were determined. The results of this study provide a reference for improving research on mixed haze and dust pollution in the future.

\section{Materials and Methods}

As Figure 1 shows, Jinan $\left(117^{\circ} 00^{\prime} \mathrm{E}, 36^{\circ} 40^{\prime} \mathrm{N}\right)$ is the capital of Shandong Province. Jinan City is located in the eastern industrial zone of China. It is a modern city that focuses on industry. In recent decades, Shandong's heavy industry has developed rapidly, and there are many steel and cement enterprises around Jinan City. The waste gas discharged into the atmosphere by these enterprises is likely to lead to the formation of atmospheric pollution such as haze. Air pollution is a frequent problem due to the long-term manmade pollution and industrial emissions [18].

In addition, Jinan is located in eastern China, where the terrain is high in the south and low in the north, and there are several small mountains to both the east and west, forming a unique semi-basin terrain in Jinan. Jinan is in the leeward direction of the Mongolian dust source; therefore, when dust is frequent in the spring, it is often affected by the Mongolian air mass, and dust weather occurs. When the weather conditions are stationary and stable, the accumulation of pollutants is more likely to occur, which is conducive to the formation of pollution weather [19]. 


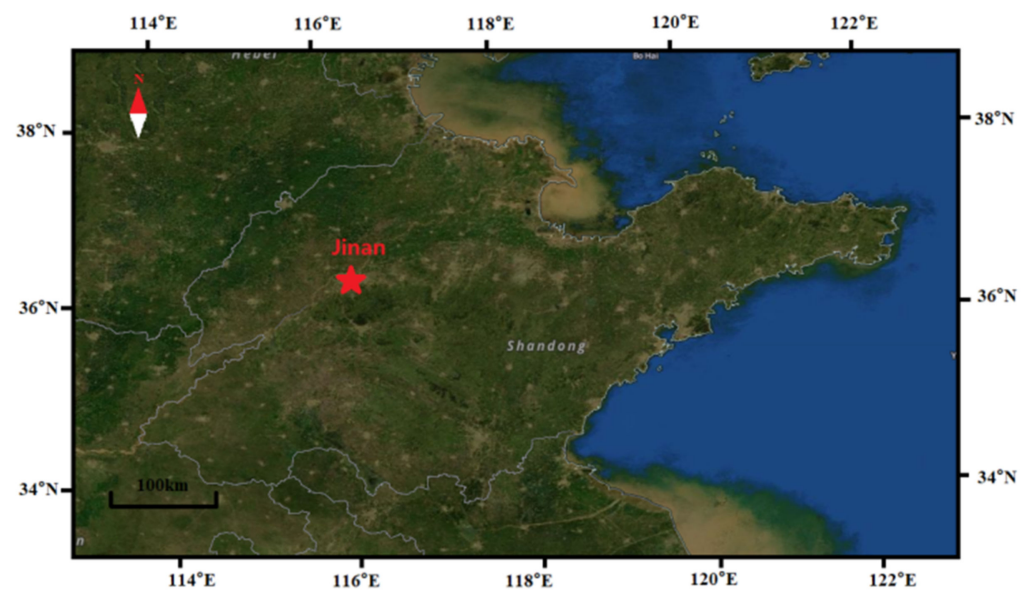

Figure 1. The geographic locations of the monitoring sites.

\subsection{Ground-Based LiDAR, Satellite Data, and Model Product}

LiDAR is a rapidly developing detection technology, which has been widely used in various fields [20]. As an atmospheric monitoring tool, LiDAR has better continuity and resolution than traditional atmospheric detection methods. LiDAR can be used to monitor various components in the atmosphere and to monitor aerosols in real time. More importantly, LiDAR allows us to study the vertical profiles of the optical properties of aerosols. The ground-based LiDAR observation point used to collect the data for this study was located on the campus of Shandong Normal University $\left(116^{\circ} 8^{\prime} \mathrm{E}, 36^{\circ} 6^{\prime} \mathrm{N}\right)$. The Mie LiDAR used in this study was capable of obtaining the morphology of the particles and analyzing the composition and spatiotemporal evolution of the aerosols by studying the depolarization characteristics of the particles. The structure and spatiotemporal evolution of the planetary boundary layer (PBL), the vertical profile and temporal evolution of the extinction coefficient of the atmospheric aerosols (dust), the atmospheric visibility, and the $\mathrm{PM}_{2.5}$ and $\mathrm{PM}_{10}$ concentrations were obtained from the LiDAR detection data. We used LiDAR to continuously monitor the distribution of atmospheric aerosols [21].

The LiDAR system consists of a laser transmitter, a receiving system, and a signal analysis and processing system. The laser radar emits a laser beam toward the target atmosphere. After receiving the backscattering signals of the interaction between the detection laser and the target, the data processing system analyzes and processes the echo signals in order to obtain the information about the particles in the target atmosphere [22,23]. This method is a common way to monitor atmospheric particulate pollution. The related parameters of the LiDAR are presented in Table 1.

Table 1. Related parameters of the Ray-GB particle LiDAR.

\begin{tabular}{cc}
\hline & Parameter \\
\hline Laser type & Pumped solid-state laser \\
Wavelength & $532 \mathrm{~nm}$ \\
Pulse energy & $\geq 1 \mathrm{~mJ}$ \\
Pulse frequency & $2000 \mathrm{~Hz}$ \\
Telescope diameter & $125 \mathrm{~mm}$ \\
Detection blind zone & $\leq 60 \mathrm{~m}$ \\
Detection distance & Maximum vertical detection height $\geq 10 \mathrm{~km} ;$ \\
Vertical resolution & Horizontal detection $\geq 10 \mathrm{~km}$ \\
& $3.75-15 \mathrm{~m}$ \\
\hline
\end{tabular}




\subsection{Inversion Method}

The aerosol LiDAR signals were obtained from the LiDAR data using Equation (1) [24].

$$
\mathrm{P}(\mathrm{z})=\frac{E C}{z^{2}} *\left[\beta_{a}(z)+\beta_{m}(z)\right] * \exp \left[-2 \int_{0}^{z} \alpha_{a}(z)+\alpha_{m}(z) d z\right],
$$

where $\beta(z)=\beta_{a}(z)+\beta_{m}(z)$, and $\alpha(z)=\alpha_{a}(z)+\alpha_{m}(z) \cdot \mathrm{P}(z)$ is the aerosol LiDAR signal at altitude $z(w)$. E denotes the fixed parameters of the emitted laser, including the laser emission power. $C$ is the speed of light $(\mathrm{m} / \mathrm{s}) . \beta_{a}(z)$ and $\beta_{m}(z)$ are the backscattering coefficients of the aerosol particles and air molecules $\left(\mathrm{km}^{-1} \cdot \mathrm{sr}^{-1}\right)$, respectively, and $\alpha_{a}(z)$ and $\alpha_{m}(z)$ are the extinction coefficients of the aerosol particles and air molecules $\left(\mathrm{km}^{-1} \cdot \mathrm{sr}^{-1}\right)$, respectively.

Compared with other methods [25,26], Fernald's method is the most commonly used, stable, and accurate inversion method [27]. Therefore, Fernald's method was used to retrieve the extinction coefficient of the aerosols. The extinction coefficient of the aerosols was obtained using Equation (2).

$$
\alpha_{a}(z)=\frac{\mathrm{P}(\mathbf{z}) \exp \left[\left(\frac{2 \mathrm{~S}_{\mathrm{a}}}{\mathrm{S}_{\mathrm{m}}}-2\right) \int_{\mathrm{z}}^{\mathrm{z}_{0}} \alpha_{\mathrm{m}}(\mathrm{z}) \mathrm{dz}\right]}{2 \int_{\mathbf{z}}^{\mathrm{z}_{0}} \mathrm{P}(\mathrm{z}) \exp \left[\left(\frac{2 \mathrm{~S}_{\mathrm{a}}}{\mathrm{S}_{\mathrm{m}}}-2\right) \int_{\mathrm{z}}^{\mathrm{z}_{0}} \alpha_{\mathrm{m}}(\mathrm{z}) \mathrm{dz}\right]+\frac{\mathrm{P}\left(\mathrm{z}_{0}\right)}{\alpha_{\mathrm{a}}\left(\mathrm{z}_{0}\right)}+\frac{\mathrm{S}_{\mathrm{a}}}{\mathrm{S}_{\mathrm{m}}} \alpha_{\mathrm{m}}\left(\mathrm{z}_{0}\right)},
$$

where $S_{a}$ is the ratio of the extinction coefficient to the backscattering coefficient for the atmospheric aerosols, i.e., the LiDAR ratio. Specifically, $S_{a}=\frac{\alpha_{a}(z)}{\beta_{a}(z)}$, and it is an empirical constant. Generally, for mainland China, 50 sr is usually chosen as the LiDAR ratio for haze particles [13]; as the LiDAR ratio for Asian dust events during the spring, a mean value of $51 \mathrm{sr}$ is generally used [28]. After considering the type of aerosol particles, we chose $S_{a}$ to be $50 \mathrm{sr}$ for mixed particles at $532 \mathrm{~nm}$. $S_{\mathrm{m}}$ is the ratio of the extinction coefficient to the backscattering coefficient for atmospheric molecules; specifically, $S_{m}=\frac{\alpha_{m}(z)}{\beta_{m}(z)}$. The LiDAR ratio for atmospheric molecules is fixed at $S_{m}=\frac{8 \pi}{3}$. From the above formula, the extinction coefficient of the aerosols can be obtained.

\subsection{Ground Station Data, Satellite Data, and Model Product}

In this study, various meteorological observations obtained from 28 to 29 March were used, and the main air pollutants included $\mathrm{PM}_{2.5}, \mathrm{PM}_{10}, \mathrm{SO}_{2}, \mathrm{NO}_{2}, \mathrm{CO}$, and $\mathrm{O}_{3}$. The hourly mean pollutant concentrations were obtained from the Changqing Party School $\left(116^{\circ} 734^{\prime} \mathrm{E}, 36^{\circ} 534^{\prime} \mathrm{N}\right)$, which is one of the sites operated by the Shandong Meteorological Bureau. In addition, the radiosonde data, including the temperature (Tem), relative humidity (RH), and wind speed (WS) in the vertical direction, as well as the meteorological data, including the hourly mean values of $\mathrm{RH}$ and temperature, were used. Both the radiosonde and meteorological data used in this study were provided by the Shandong Meteorological Bureau.

The satellite monitoring data used in this study were collected by CALIPSO [29], which was jointly developed by the National Aeronautics and Space Administration (NASA) and the Centre National d'Etudes Spatiales (CNES). CALIPSO is the first global satellite for the observation of clouds and aerosols, and it provides the physical characteristics and temporal and spatial distribution of clouds and aerosols, which is helpful in studying the formation, development, and interactions of clouds and aerosols [30].

In order to determine the aerosol transport trajectory, the Hybrid Single-Particle Lagrangian Integrated Trajectory (HYSPLIT) model [31] was used. The HYSPLIT model is a professional model that was developed by the National Oceanic and Atmospheric Administration (NOAA). It is used to calculate and analyze the transport and diffusion trajectory of air pollutants. The HYSPLIT model was used to calculate the backward trajectory and to identify the source of the polluted air mass and its path. 


\section{Results}

From 25 to 30 March 2021, a serious mixed haze and dust pollution event occurred in Jinan, China. This mixed pollution was observed and analyzed using ground-based LiDAR and satellite LiDAR. Figure 2 presents the Moderate Resolution Imaging Spectroradiometer (MODIS) true color images acquired during the pollution event in the Jinan area.

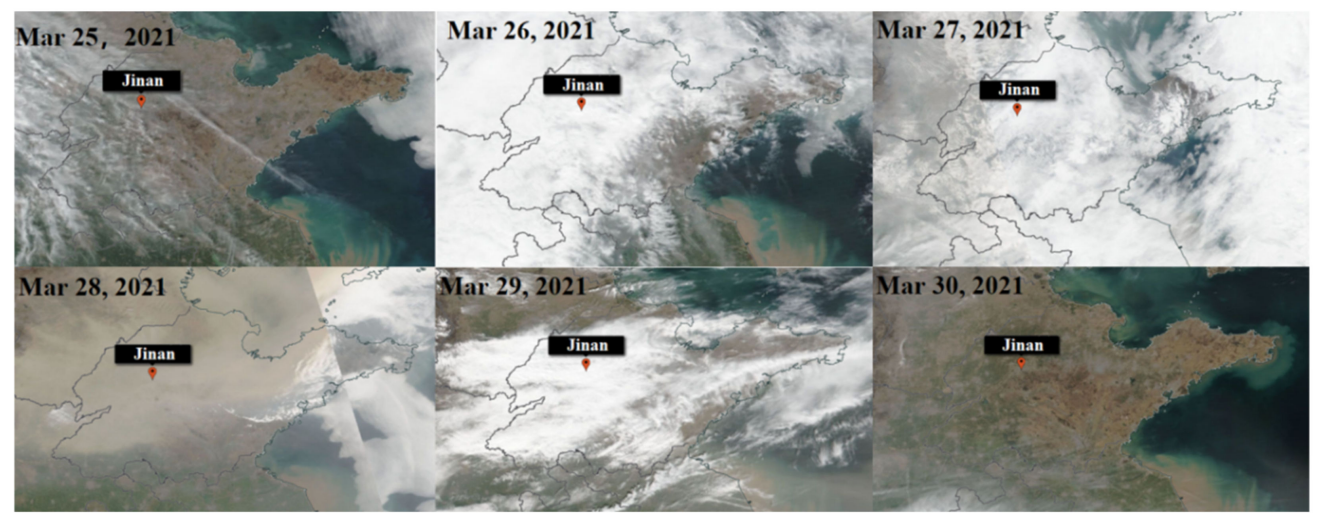

Figure 2. Visible Infrared Imaging Radiometer Suite (VIIRS) Suomi NPP 6 km true color images acquired during the pollution event investigated in this study.

\subsection{Transboundary Aerosol Transport Observed by the CALIPSO Satellite}

Figure 3 shows the dust transport process observed by CALIOP during the 28 March mission. The variations in the aerosols in the vertical direction from the source to the study area can be seen. As can be seen from Figure 3, on 28 March, a large amount of dust was distributed 1-4 km above Jinan, and the height of the dust was relatively low. It should be noted that, at the bottom of the dust, pollution dust appeared in combination with ground pollution, forming mixed haze and dust pollution. According to the backward transmission trajectory, the power of the northwest wind was conducive to the eastward transmission of the dust. The dust settled near the surface and combined with the near-surface aerosol pollution to form polluted dust.

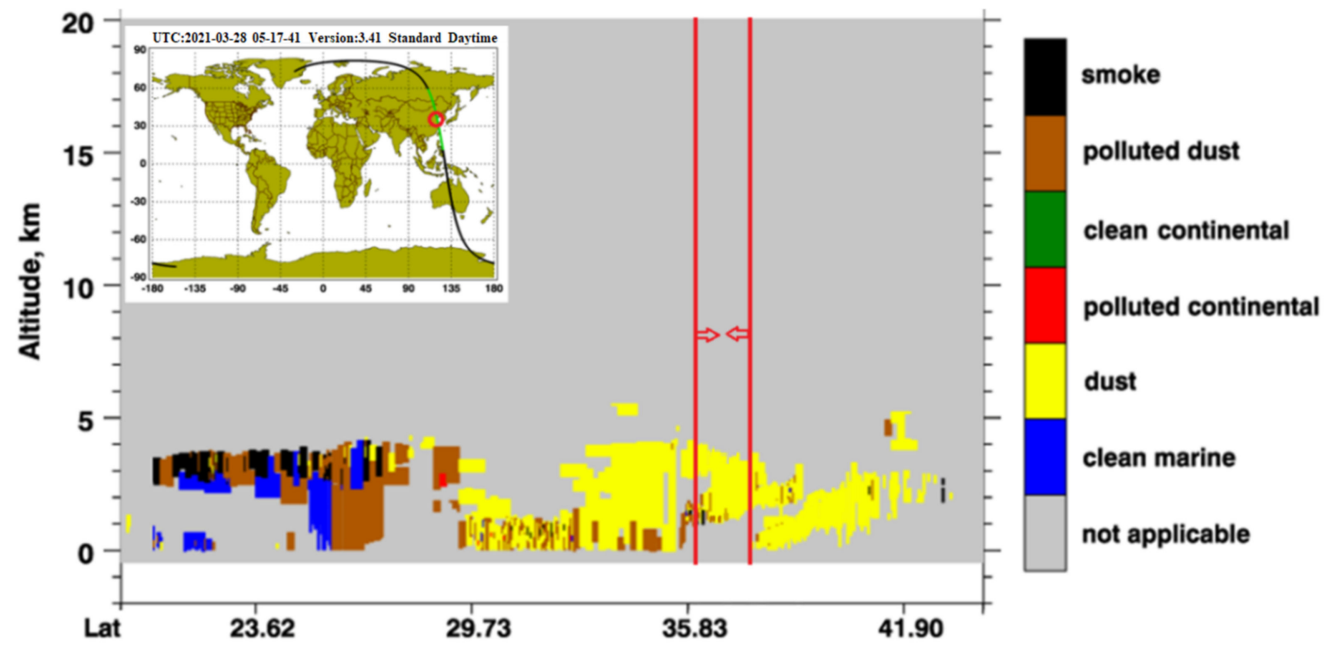

Figure 3. The vertical continuous detection by CALIPSO: aerosol subtypes on 28 March 2021.

\subsection{Ground-Based LiDAR Observations of Aerosols}

Figure 4 shows the vertical distribution of the extinction coefficient obtained via LiDAR at the experimental site on 28 March and 29 March. On the basis of the LiDAR observations, the pollution was divided into three stages, combined with the meteorological data from Sections 3.4 and 3.5 for comprehensive analysis. Stage 1 was From 12:00 a.m. to 8:00 a.m. 
on 28 March, and the boundary layer height was about $1.7 \mathrm{~km}$. At this time, the humidity increased, the wind was static and stable, the diffusion conditions became worse, and the concentration of particles near the surface gradually increased. Stage 2 was from 8:00 a.m. on 28 March to 4:00 a.m. on 29 March. During this period, high-altitude pollution input was detected around 9:00 a.m., and the particle concentration increased significantly. As the humidity increased to the maximum, the diffusion conditions of the particles became unfavorable, the LiDAR observed that the pollution entered a stable period. They gradually gathered on the ground, and the pollution intensified further. This phase lasted until 4:00 a.m. on 29 March. During Stage 3, the humidity decreased, the wind level increased, and the planetary boundary layer rose steadily. The overall environmental conditions were conducive to the diffusion of particle pollution. The concentration of the near-surface pollutants decreased, and the environmental pollution index began to improve. The RH and WS are discussed in detail in the next section.
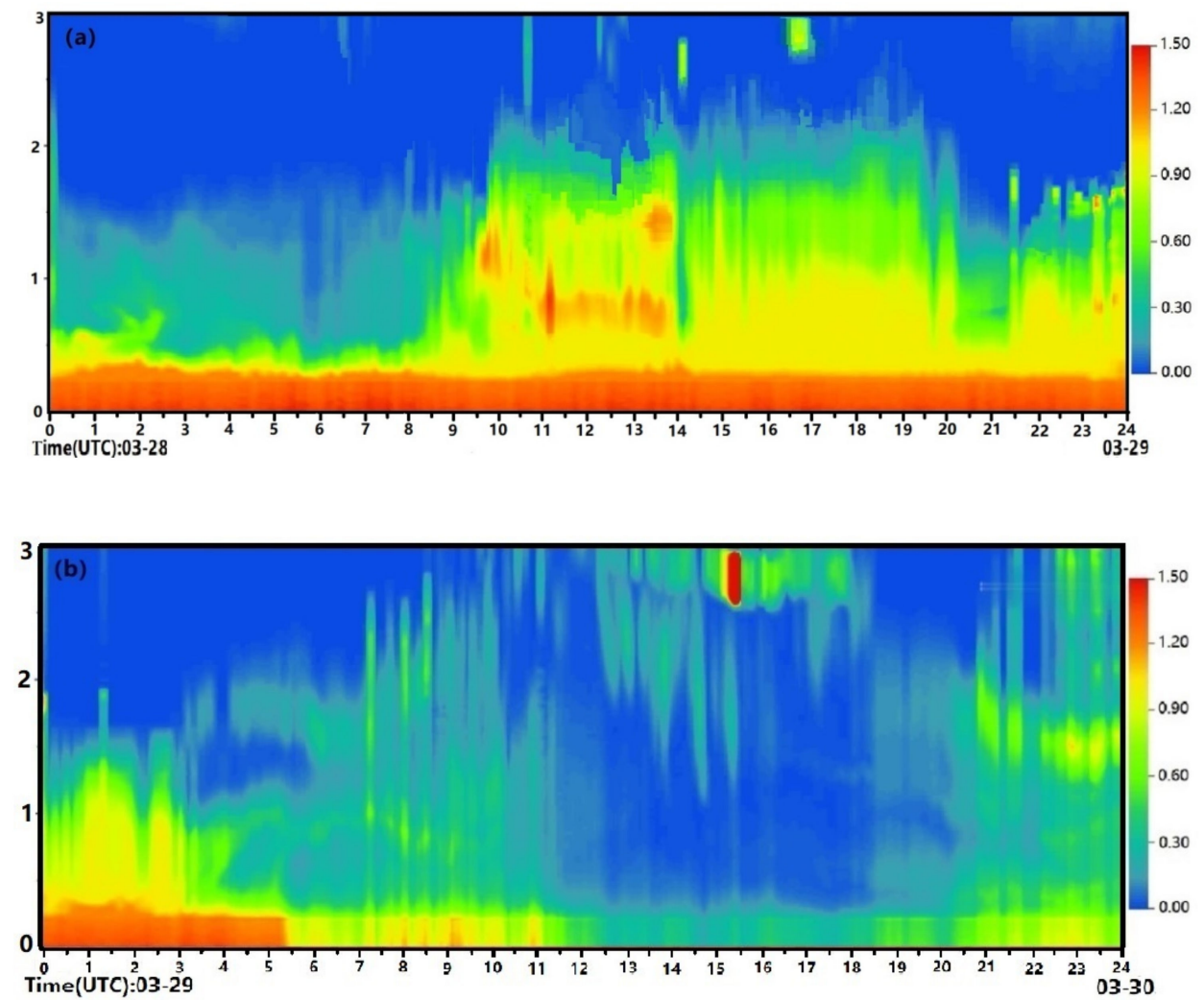

Figure 4. Vertical profile of the extinction coefficient of the aerosols within $3 \mathrm{~km}$ above the ground observed via LiDAR in Jinan: (a) 28 March 2021; (b) 29 March 2021.

\subsection{Ground Station Meteorological Measurements}

The concentrations of six standard air pollutants during this pollution event are shown in the chart.

As can be seen from Figure 5, in the early stage, the pollution was predominantly haze, the $\mathrm{PM}_{10}$ concentration was relatively low, basically below $150 \mu \mathrm{g} / \mathrm{m}^{3}$, and the $\mathrm{PM}_{2.5}$ concentration was relatively high, with an average concentration of about $80 \mu \mathrm{g} / \mathrm{m}^{3}$. Affected by the Mongolian air mass, dust began to affect Jinan at 9:00 a.m. on 28 March, and the $\mathrm{PM}_{2.5}$ and $\mathrm{PM}_{10}$ concentrations simultaneously increased rapidly. They both reached their maximum values at 6:00 p.m., with the $\mathrm{PM}_{2.5}$ concentration reaching $213 \mu \mathrm{g} / \mathrm{m}^{3}$ and the $\mathrm{PM}_{10}$ concentration reaching $1230 \mu \mathrm{g} / \mathrm{m}^{3}$. Then, the concentrations began to decrease and returned to a steady state at 4:00 p.m. on 29 March. Accordingly, the AQI index reached a peak of 500 at 2:00 p.m. on $28 \mathrm{March}$ and lasted $15 \mathrm{~h}$. It did not start to gradually decrease until 5:00 p.m. on 29 March, and the air quality gradually improved. By 6:00 p.m., the pollution event had basically ended, and the pollution had eased. 


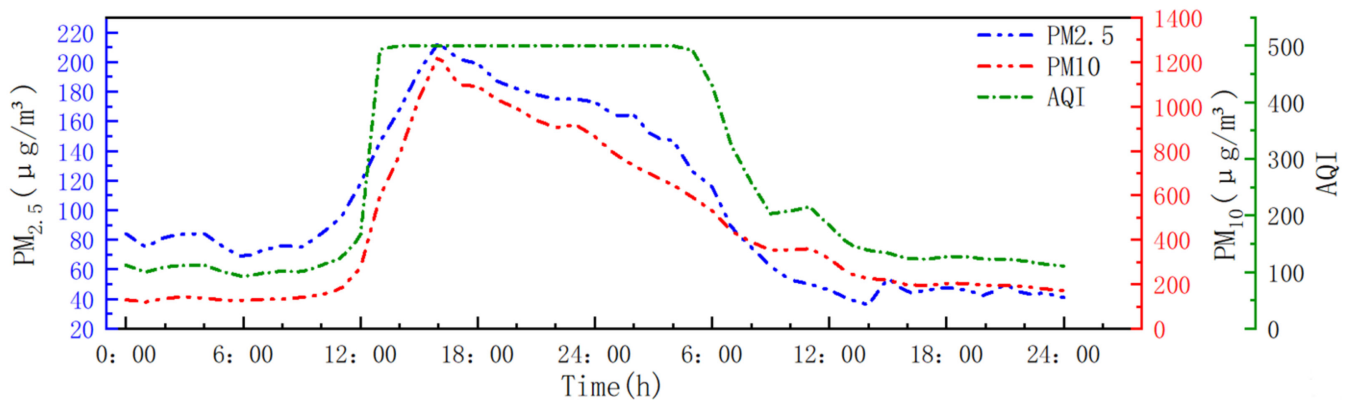

Figure 5. Changes in the PM2.5 and PM10 concentrations with time.

\subsection{Analysis of the Meteorological Conditions and Pollutant Concentrations}

Figure 6 shows the relationships between the meteorological factors and the particulate matter. As can be seen from Figure 6, the $\mathrm{PM}_{2.5}$ concentration and relative humidity exhibited roughly the same trends. This is due to the fact that, at the beginning of the haze event, the relative humidity was high, and the main inorganic salts in the aerosol particles, such as sulfate and nitrate, were highly hygroscopic substances; thus, they absorbed the moisture in the air, which increased the particle size. As a result, the possibility of multiphase reactions increased, leading to increased contamination. It can be seen that the higher humidity was more conducive to increasing the particle concentration and to the formation of secondary pollution.
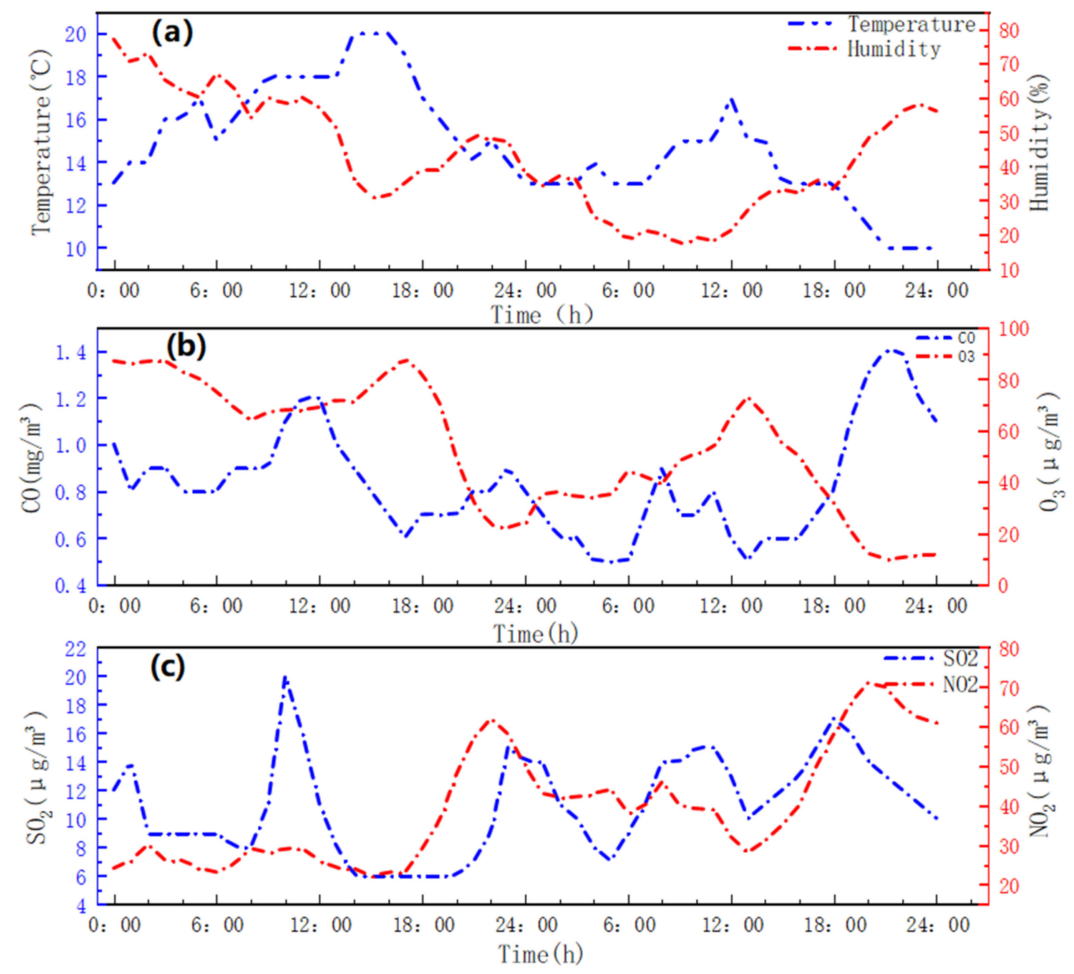

Figure 6. Comparison of the amplitudes of the changes on 27 and 28 March 2021: (a) temperature and relative humidity $(\mathrm{RH}) ;(\mathbf{b}) \mathrm{CO}$ and $\mathrm{O}_{3} ;$ (c) $\mathrm{SO}_{2}$ and $\mathrm{NO}_{2}$.

When air pollution occurs, the static state of the atmosphere is more unfavorable to the diffusion of pollution. In the early stage of pollution, an inversion layer often appears in the vertical direction. The inversion layer obstructs the vertical movement of the air and is not conducive to the dilution and diffusion of pollutants. This is more likely to cause the pollutants to accumulate on the ground, leading to serious pollution. Figure 7 shows the vertical profiles of the temperature, humidity, and wind conditions at the weather stations near the study area on 28 March. It can be seen that, at the early stage of the pollution, 
temperature inversion occurred above the surface, and the height of the inversion layer was about $2000 \mathrm{~m}$. At this height, the average wind speed was low, which was not conducive to horizontal diffusion. In addition, the air humidity changed greatly.
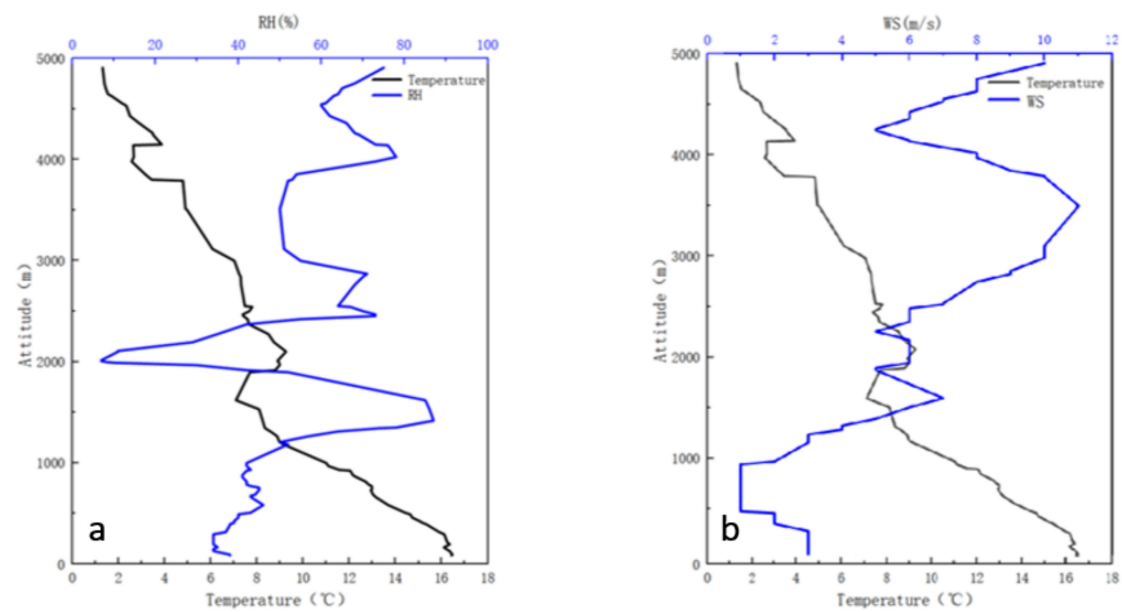

Figure 7. Vertical profiles of the temperature, RH, and WS over Jinan (28 March 2021): (a) temperature and RH profiles on 28 March 2021; (b) temperature and WS profiles on 28 March 2021.

On the basis of the relationships between the various meteorological conditions and the pollutant concentrations described above, it can be seen that, when the wind speed was low, an inversion layer appeared in the vertical direction, which obstructed the horizontal and vertical diffusion, leading to further aggravation of the pollution.

\subsection{HYSPLIT Backward Trajectory and Weather Condition Analysis}

In order to analyze the source and path of the air mass described above, Figure 8 shows the backward trajectory based on the HYSPLIT model both near the ground and at a high altitude. The reference point was Jinan $\left(36^{\circ} 40^{\prime} \mathrm{N}, 117^{\circ} 00^{\prime} \mathrm{E}\right)$, and the research time was the 48 h period before 12:00 p.m. on 28 March 2021. As can be seen from Figure 8a, the high-altitude transmission route of this pollution event was roughly in the northwest direction, and the air mass from Mongolia was the main source of this pollution above a height of $1000 \mathrm{~m}$. Affected by the airflow, these air masses carried a large amount of dust particles, passed through Inner Mongolia, Hebei, and other places, and imported a large amount of dust into the Jinan area. Figure $8 \mathrm{~b}$ shows that the low-altitude transmission below $500 \mathrm{~m}$ mainly originated in Hebei and other regions, which can be inferred to be industrial pollution emissions and manmade pollution from the surrounding areas. At a height of $1500 \mathrm{~m}$, the air mass from Mongolia was the main source of pollution. Affected by the airflow, these air masses carried dust particles, and a large amount of dust was imported into the Jinan area. Due to the influences of the other meteorological factors, the diffusion conditions in the boundary layer were poor, and the dust combined with the aerosols near the surface to form mixed aerosol and dust pollution, which further worsened the level of pollution.

The pollutant concentration, meteorological factors, radiosonde data, CALIPSO satellite data, and back-trajectory analysis were employed in the study. On the basis of all observations, the serious mixed pollution of haze and dust that occurred in Jinan was studied. Haze played a dominant role in the early stage of pollution, and the RH increased during haze. Under the condition of high relative humidity, main inorganic salts in the aerosol particles such as sulfate and nitrate absorbed the moisture in the air, increased the particle size and pollution concentration, and generated sulfate and nitrate aerosols, resulting in the aggravation of smog. The dust transportation process was observed in CALIPSO on $28 \mathrm{March}$. The dust settled near the surface and combined with the near-surface polluted aerosol to form polluted dust. During the pollution, an inversion layer appeared about 
$2000 \mathrm{~m}$ in the vertical direction. The inversion layer hindered the vertical movement of air, leading to the stagnation of the weather. Combined with the above observations, the atmospheric conditions were not conducive to diffusion, because the near-surface and inversion layers with high RS and low WS, together with the input of dust particles, all led to mixed pollution.
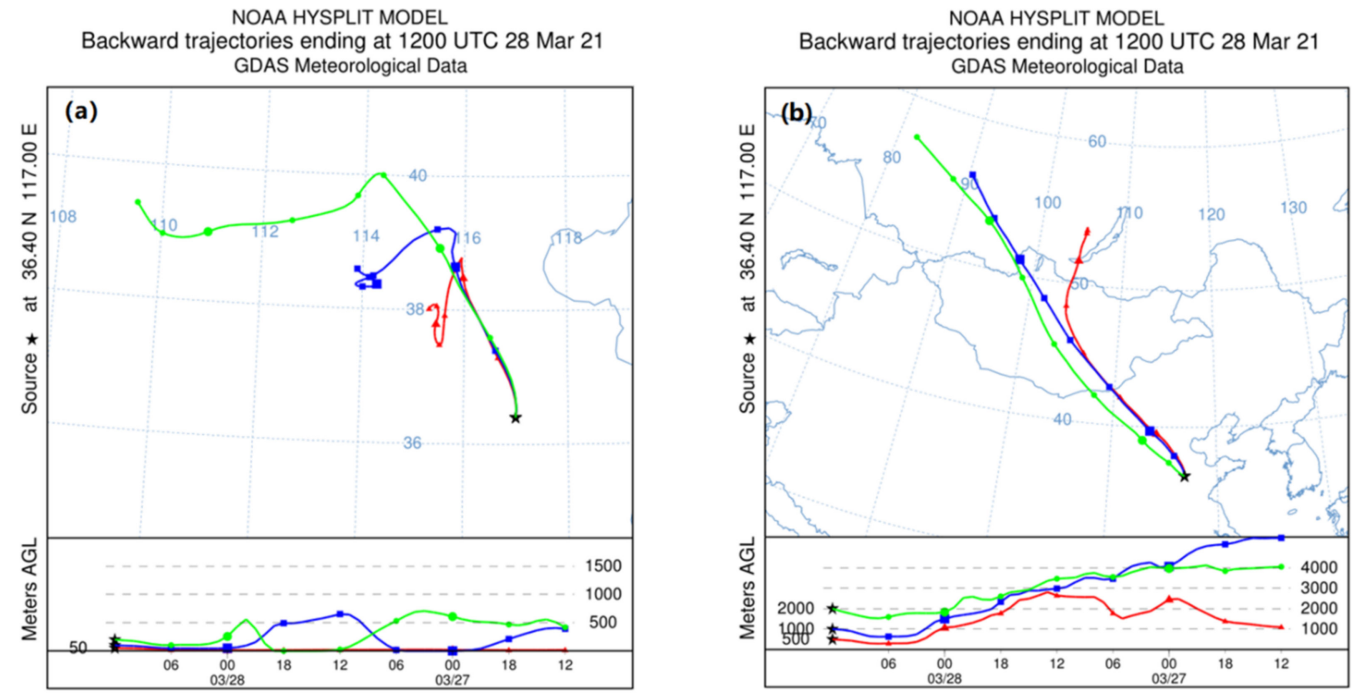

Figure 8. The $48 \mathrm{~h}$ backward trajectories: (a) low-altitude backward trajectory at 12:00 p.m. on 28 March; (b) high-altitude backward trajectory at 12:00 p.m. on 28 March.

\section{Discussion}

In this study, LiDAR was used to observe the mixed haze and dust pollution in Jinan in March 2021. The transport routes and sources of the dust were analyzed on the basis of meteorological parameters and by tracking the pollution sources, including CALIPSO satellite radar and HYSPLIT backward trajectory analysis.

The results of this study are summarized below.

1. According to radar data and a variety of observations, in this study, a smog/dust pollution process in Jinan was analyzed. The results show that, during the pollution period, the static stability of the atmosphere was good, the humidity was high, and an inversion layer formed, which was conducive to the accumulation of particulate matter. Due to the influx of dust, the main pollutants in the air changed from $\mathrm{PM}_{2.5}$ to $\mathrm{PM}_{10}$, and the pollution increased rapidly. As the humidity decreased, the atmospheric boundary layer rose, the pollution gradually eased, and the pollution incident largely ended on the 30 March.

2. The time, source, and cause of the haze and dust pollution in Jinan were different. After $27 \mathrm{March}$, the $\mathrm{PM}_{2.5}$ concentration in Jinan increased, while the dust pollution was transmitted into the study area on 28 March. After settling, it combined with the near-surface aerosols to form polluted dust. During the pollution period, the dust was mainly supplied by an air mass from Inner Mongolia, while the near-surface pollution was caused by industrial emissions and automobile exhaust. The meteorological factors were not conducive to pollution diffusion, which led to deposition of the pollution.

3. According to the spatial distribution characteristics of the $\mathrm{PM}_{2.5}$ and $\mathrm{PM}_{10}$, the nearsurface aerosol pollution was very serious. Due to the severe population in Jinan, the mixed haze, sand, and dust pollution had a great impact to people's lives. Surrounding industrial sites should also pay attention to reasonable emissions to reduce air pollution.

By observing the pollution events in the Jinan area via LiDAR and satellite, we obtained the relevant information about and variation characteristics of the main pollution particles, 
which is an effective means of studying aerosol pollution. Due to its special geographic location, Jinan has a rare small basin terrain; therefore, it is easier for particles to accumulate and form air pollution. Unlike studies of only haze events (i.e., without dust), in this study, the phenomenon of haze pollution transforming into dust pollution in Jinan was analyzed, and the synergistic relationship between the various meteorological factors during the pollution event was obtained. The results of this study provide a reference for further study of the frequent mixed pollution events in spring in Jinan.

Although the analysis of this weather process in this paper can provide a research basis for mixed pollution in Jinan area, the LiDAR observations and meteorological data in this paper are still slightly limited. In order to better understand the influence of weather change on pollution causes, it is necessary to study the local atmospheric circulation in more detail, such as boundary layer height, wind field at different vertical heights, and other meteorological fields. In the future, we will make long-term observations of LiDAR and multivariate data, as well as collect more typical lidar observation samples. Additional effort should be made to investigate the long-distance transportation of dust using numerical models, so as to better understand the influence of cross-border dust events on air quality.

Author Contributions: Conceptualization, Y.Z. and Y.W.; investigation, Y.W.; methodology, Y.Z. and Y.W.; project administration, Y.Z. and J.W.; supervision and visualization, J.F. and M.Z.; writingoriginal draft, Y.Z. and Y.W.; writing-review and editing, M.Z. and C.L. All authors have read and agreed to the published version of the manuscript.

Funding: This research was funded by the National Natural Science Foundation of China (No.62002208) and the Natural Science Foundation of Shandong Province (No. ZR2019MA028, No. ZR2020MA082).

Data Availability Statement: No new data were created or analyzed in this study. Data sharing is not applicable to this article.

Conflicts of Interest: The authors declare no conflict of interest.

\section{References}

1. Wu, X.Y.; Xin, J.Y.; Zhang, W.Y.; Gong, C.S.; Wu, F.K. Optical, Radiative and Chemical Characteristics of Aerosol in Changsha City, Central China. Adv. Atmos. Sci. 2020, 37, 1310-1322. [CrossRef]

2. Che, H.Z.; Xia, X.A.; Zhu, J.; Wang, H.; Wang, Y.Q.; Sun, J.Y.; Zhang, X.Y.; Shi, G.Y. Aerosol optical properties under the condition of heavy haze over an urban site of Beijing, China. Environ. Sci. Pollut. Res. 2015, 22, 1043-1053. [CrossRef] [PubMed]

3. Lee, K.H.; Kim, Y.J.; Kim, M.J. Characteristics of aerosol observed during two severe haze events over Korea in June and October 2004. Atmos. Environ. 2006, 40, 5146-5155. [CrossRef]

4. Li, Z.Q.; Guo, J.P.; Ding, A.J.; Liao, H.; Liu, J.J.; Sun, Y.L.; Wang, T.J.; Xue, H.W.; Zhang, H.S.; Zhu, B. Aerosol and boundary-layer interactions and impact on air quality. Natl. Sci. Rev. 2017, 4, 810-833. [CrossRef]

5. Zhou, X.H.; Ni, C.J.; Tan, G.R. Characteristics and Cause Analysis of a Persistent Haze Process in Southern Sichuan Basin. Plateau Mt. Meteorol. Res. 2018, 38, 53-57. [CrossRef]

6. Li, H.B.; Liu, Y.Q.; Yao, S.Q.; Jin, Y.F.; Wu, W.D. Short term exposure to haze air pollution induces acute airway inflammation and lung function reduction in healthy adult subjects. J. Environ. Anal. Toxicol. 2018, 8, 555. [CrossRef]

7. Chen, Q.C.; Sun, H.Y.; Mu, Z.; Wang, Y.Q.; Li, Y.G.; Zhang, L.X.; Wang, M.M.; Zhang, Z.M. Characteristics of environmentally persistent free radicals in $\operatorname{PM}(2.5)$ : Concentrations, species and sources in Xi'an, Northwestern China. Environ. Pollut. 2019, 247, 18-26. [CrossRef]

8. Cohen, J.B.; Wang, C.E. Estimating global black carbon emissions using a top-down Kalman Filter approach. J. Geophys. Res. Atmos. 2014, 119, 307-323. [CrossRef]

9. Guo, J.; Deng, M.; Lee, S.S.; Wang, F.; Li, Z.; Zhai, P.; Liu, H.; Lv, W.; Yao, W.; Li, X. Delaying precipitation and lightning by air pollution over the Pearl River Delta. Part I: Observational analyses. J. Geophys. Res. Atmos. 2016, 121, 6472-6488. [CrossRef]

10. Guo, J.P.; Lou, M.Y.; Miao, Y.C.; Wang, Y.; Zeng, Z.L.; Liu, H.; He, J.; Xu, H.; Wang, F.; Min, M.; et al. Trans-Pacific transport of dust aerosols from East Asia: Insights gained from multiple observations and modeling. Environ. Pollut. 2017, 230, 1030-1039. [CrossRef]

11. Ho, H.C.; Wong, M.S.; Yang, L.; Chan, T.C.; Bilal, M. Influences of socioeconomic vulnerability and intra-urban air pollution exposure on short-term mortality during extreme dust events. Environ. Pollut. 2018, 235, 155-162. [CrossRef]

12. Xu, R.; Zhang, H.D.; Yang, X.W.; Cheng, S.Y.; Zhang, T.H.; Jing, Q. Concentration characteristics of PM 2.5 and the causes of heavy air pollution events in Beijing during autumn and winter. Environ. Sci. 2019, 40, 3405-3414. [CrossRef] 
13. Xiang, Y.; Lv, L.L.; Chai, W.X.; Zhang, T.S.; Liu, J.G.; Liu, W.Q. Using LiDAR technology to assess regional air pollution and improve estimates of PM2.5 transport in the North China Plain. Environ. Res. Lett. 2020, 15, 094071. [CrossRef]

14. Fu, S.L.; Xie, C.B.; Zhuang, P.; Tian, X.M.; Zhang, Z.Y.; Wang, B.X.; Liu, D. Study of Persistent Foggy-Hazy Composite Pollution in Winter over Huainan Through Ground-Based and Satellite Measurements. Atmosphere 2019, 10, 656. [CrossRef]

15. Lei, X.; Qian, Y.F.; Zhong, L.J.; Quan, Q.M. Analysis of a Dust Pollution Process in Nanchong City Based on Particulate LiDAR. SiChuan Environ. 2017, 36, 93-102.

16. Yang, H.; Fang, Z.Y.; Cao, Y.; Xie, C.B.; Zhou, T.; Wang, B.X.; Xing, K.; Lolli, S. Impacts of Transboundary Dust Transport on Aerosol Pollution in the Western Yangtze River Delta Region, China: Insights Gained From Ground-Based Lidar and Satellite Observations. Earth Space Sci. 2021, 8. [CrossRef]

17. Zhang, H.; Zhang, B.; Lv, M.Y.; AN, L.C.; Centre, N.M. Development and application of stable weather index of Beijing in environmental meteorology. Meteorol. Mon. 2017, 43, 998-1004.

18. Xiong, Y.; Tang, Y.; Kou, X.; Li, Z.M.; Sun, Z.; Lu, B. Analysis of a Haze and Sand-dust Mixed Pollution Weather in Spring of Beijing. J. Arid. Meteorol. 2017, 35, 100-107. [CrossRef]

19. Wu, Q.; Zhou, W.F.; Zhang, L. China's environment: Challenges and solutions. Environ. Earth Sci. 2011, 64, 1503-1504.

20. Xu, Z.Y.; Yu, F.X.; Qiu, B.; Zhang, Y.W.; Xiang, Y.; Pan, S. Coherent Random-Modulated Continuous-Wave LiDAR Based on Phase-Coded Subcarrier Modulation. Photonics 2021, 8, 475. [CrossRef]

21. Xie, C.B.; Zhao, M.; Wang, B.X.; Zhong, Z.Q.; Wang, L.; Liu, D.; Wang, Y. Study of the scanning LiDAR on the atmospheric detection. J. Quant. Spectrosc. Radiat. Transf. 2015, 150, 114-120. [CrossRef]

22. Zhao, H.J.; Che, H.Z.; Wang, Y.Q.; Dong, Y.S.; Ma, Y.J.; Li, X.X.; Hong, Y.; Yang, H.B.; Liu, Y.C.; Wang, Y.F.; et al. Aerosol vertical distribution and typical air pollution episodes over northeastern China during 2016 analyzed by ground-based lidar. Aerosol Air Qual. Res. 2018, 18, 918-937. [CrossRef]

23. Song, T.; Liu, J.Z.; Hu, T.T.; Sheng, S.J.; Yan, F.; Dong, M.; Zhou, W.L.; Wu, X. Application of Atmospheric Particles Monitoring based on MODIS Aerosol Optical Thickness Products and Laser Radar. Remote Sens. Technol. Appl. 2016, 31, $397-404$.

24. Anna, K.J.; Tadeusz, S.; Grzegorz, K.; Michal, P.; Szymon, P.M. Particle size distribution retrieval from multi wavelength LiDAR signals for droplet aerosol. Appl. Opt. 2009, 48, B8-B16. [CrossRef]

25. Kovalev, V.A. LiDAR measurement of the vertical aerosol extinction profiles with range-dependent backscatter-to-extinction ratios. Appl. Opt. 1993, 32, 6053-6065. [CrossRef]

26. Klett, J.D. Stable analytical inversion solution for processing LiDAR returns. Appl. Opt. 1981, 20, 211-220. [CrossRef]

27. Fernald, F.G. Analysis of atmospheric LiDAR observations: Some comments. Appl. Opt. 1984, 23, 652-653. [CrossRef]

28. Liu, Z.Y.; Sugimoto, N.; Murayama, T. Extinction-to-backscatter ratio of Asian dust observed with high-spectral-resolution lidar and Raman lidar. Appl. Opt. 2002, 41, 2760-2767. [CrossRef]

29. Winker, D.M.; Vaughan, M.A.; Omar, A.; Hu, Y.; Powell, K.A.; Liu, Z.; Young, S.A. Overview of the CALIPSO mission and CALIOP data processing algorithms. J. Atmos. Ocean. Technol. 2009, 26, 2310-2323. [CrossRef]

30. Wu, Y.H.; Cordero, L.; Gross, B.; Moshary, F.; Ahmed, S. Assessment of CALIPSO attenuated backscatter and aerosol retrievals with a combined ground-based multi-wavelength LiDAR and sunphotometer measurement. Atmos. Environ. 2014, 84, 44-53. [CrossRef]

31. Cai, Z.; Jiang, F.; Chen, J.M.; Jiang, Z.Q.; Wang, X.Y. Weather condition dominates regional PM2.5 pollutions in the eastern coastal provinces of China during winter. Aerosol Air Qual. Res. 2018, 18, 969-980. [CrossRef] 